\title{
Immunological consequences following splenectomy in patients with liver cirrhosis
}

\author{
YUSUKE HIRAKAWA ${ }^{1}$, TOSHIRO OGATA ${ }^{1,2^{*}}$, TETSURO SASADA ${ }^{3,4^{*}}$, TAKUTO YAMASHITA $^{5}$, \\ KYOGO ITOH $^{3}$, HIROYUKI TANAKA ${ }^{1}$ and KOJI OKUDA ${ }^{1}$
}

\author{
${ }^{1}$ Department of Surgery, Kurume University School of Medicine, Kurume, Fukuoka 830-0011; ${ }^{2}$ Department of Surgery, \\ St. Mary's Hospital, Kurume, Fukuoka 830-8543; ${ }^{3}$ Cancer Vaccine Center, Kurume University, Kurume, \\ Fukuoka 839-0863; ${ }^{4}$ Cancer Vaccine Center, Kanagawa Cancer Center, Yokohama, Kanagawa 241-8515; \\ ${ }^{5}$ Biostatistics Center, Kurume University, Kurume, Fukuoka 830-0011, Japan
}

Received October 6, 2018; Accepted May 16, 2019

DOI: $10.3892 /$ etm.2019.7640

\begin{abstract}
The immune status in patients with liver cirrhosis is generally impaired due to concomitant hypersplenism. As the spleen is the largest lymphoid organ, deleterious events resulting from splenectomy are of concern in these patients. However, the immunological consequences after splenectomy have not yet been fully elucidated. In the present study, the immune status after splenectomy was comprehensively examined. Splenectomy was performed in 11 patients with liver cirrhosis and hypersplenism, and the immune status in peripheral blood was examined and compared before and at 1 , 3 and 6 months after splenectomy. Splenectomy significantly lowered the neutrophil-to-lymphocyte ratio, due to a surge in lymphocytes in the peripheral circulation at 3 and 6 months after splenectomy. The frequency of cluster of differentiation $(\mathrm{CD}) 4^{+} \mathrm{T}$ cells decreased after splenectomy, whereas the frequency of $\mathrm{CD}^{+} \mathrm{T}$ cells increased. Notably, the frequencies of the naïve and central memory subsets of $\mathrm{CD}^{+}$and $\mathrm{CD} 8^{+}$ $\mathrm{T}$ cells decreased, whereas those of the effector memory subset trended upward. In addition, the frequencies of other immune cells such as $\gamma \delta \mathrm{T}$ cells, natural killer T cells and natural killer cells transiently increased, while inhibitory cells such as regulatory $\mathrm{T}$ cells and myeloid-derived suppressor cells significantly decreased. T-cell responses to viral- and tumor-associated antigens increased after splenectomy in five
\end{abstract}

Correspondence to: Dr Toshiro Ogata, Department of Surgery, St. Mary's Hospital, 422 Tsubukuhonmachi, Kurume, Fukuoka 830-8543, Japan

E-mail: ogacchi@med.kurume-u.ac.jp

Dr Tetsuro Sasada, Cancer Vaccine Center, Kanagawa Cancer Center, 2-3-2 Nakao, Yokohama, Kanagawa 241-8515, Japan

E-mail: tsasada@kcch.jp

${ }^{*}$ Contributed equally

Key words: liver cirrhosis, splenectomy, hypersplenism, immune status, neutrophil-to-lymphocyte ratio, immune cell phenotype, $\mathrm{T}$ cell of eight and two of five patients, respectively. To the best of our knowledge, this is the first study to precisely examine the drastic changes of immunological phenotypes in peripheral blood after splenectomy in patients with cirrhosis. Our findings suggested that splenectomy in patients with cirrhosis may ameliorate the impaired immune status, possibly by reducing suppressive cells and enhancing the effector cell population and function, which could, at least in part, explain the mechanisms responsible for the clinical benefits of splenectomy.

\section{Introduction}

Patients with liver cirrhosis are generally regarded as immunocompromised (1). Not only does bacterial infection develop in 14.5 to $34.0 \%$ of patients with liver cirrhosis (2), but community-acquired infections are also frequently observed in patients with more advanced liver cirrhosis. Because the spleen is the largest lymphoid organ in the body with concentrated amounts of $\mathrm{T}$ and $\mathrm{B}$ cells, macrophages, and dendritic cells, splenectomy in patients with cirrhosis has produced concern over decreased tumor immunity and an elevated risk of infection, such as overwhelming pneumococcal sepsis (3-5).

Thrombocytopenia has been known to be an important factor that interferes with treatment of hepatocellular carcinoma and chronic liver diseases (6). We previously reported that splenectomy in patients with advanced cirrhosis corrected thrombocytopenia, improved liver function, reduced portal venous pressure, and allowed prolonged management of hepatocellular carcinoma (HCC) and hepatitis $\mathrm{C}$ virus (HCV) infection (7). Other researchers have also described the clinical benefits of splenectomy in the management of portal hypertension (8,9), HCC (10), and living-donor liver transplantation (11) among patients with liver cirrhosis. In addition, Zhang et al reported that synchronous splenectomy and hepatectomy improved the disease-free survival rate compared with hepatectomy alone (12). Although the clinical merits of splenectomy for patients with cirrhosis have been reported, the possible immunological advantages have not yet been fully explored.

In the present study, we examined the effects of splenectomy on the neutrophil-to-lymphocyte ratio (NLR), an indicator 
of systemic inflammation and cancer outcomes $(13,14)$, and phenotypes of various immune cells among peripheral blood mononuclear cells (PBMCs). Immune responses against viral- and tumor-associated antigens were also assessed and compared before and after splenectomy. Our results suggested that splenectomy might ameliorate the impaired immune status in patients with liver cirrhosis, possibly by reducing suppressive cell fractions and enhancing the effector cell population and function, which could, at least in part, explain the mechanisms responsible for clinical benefits of splenectomy.

\section{Patients and methods}

Patients. Eleven patients with liver cirrhosis and hypersplenism underwent hand-assisted laparoscopic splenectomy at the Department of Surgery of Kurume University Hospital. Six patients were male and five were female, with a median age of 65 years (range, 44-75 years). Five and six patients were classified as having Child-Pugh class A and B liver disease, respectively. Ten patients were HCV-positive and the remaining patient had alcoholic cirrhosis. Six patients had HCC. We performed splenectomy in an attempt to either manage thrombocytopenia caused by hypersplenism and thus facilitate anti-HCC treatment by improving liver function $(n=6)$ or to prevent further thrombocytopenia caused by interferon treatment in patients with $\mathrm{HCV}(n=5)$. The patients with HCC received simultaneous radiofrequency ablation to treat hepatic lesions. Because prevalence of portal thrombosis after splenectomy in patients with liver cirrhosis was high $(7,15)$, we performed prophylactic anticoagulation using danaparoid sodium and warfarin potassium to prevent portal thrombosis after splenectomy, as previously reported (7).

Along with careful clinical observations, the white blood cell (WBC), lymphocyte, neutrophil, and platelet counts were measured in the peripheral blood before and at 1,3, and 6 months after splenectomy. The NLR was defined as the absolute neutrophil count divided by the absolute lymphocyte count. The study was conducted in accordance with the provisions of the Declaration of Helsinki and was approved by the Institutional Review Board at Kurume University Hospital. Before surgery, possible undesirable outcomes were explained to all patients involved in the study, and written informed consent was obtained from all patients.

Immune cell phenotypes. Immune cell phenotypes were determined by flow cytometry. A total of $30 \mathrm{ml}$ of peripheral blood was serially obtained immediately before and at 1, 3, and 6 months after splenectomy. PBMCs were isolated by density gradient centrifugation with the Ficoll-Paque Plus (GE Healthcare, Uppsala, Sweden) and frozen until analysis. After thawing, PBMCs $\left(5 \times 10^{5}\right.$ cells $)$ were suspended in phosphate-buffered saline (PBS) containing 2\% fetal bovine serum (MP Biologicals, Solon, OH, USA) and incubated for $30 \mathrm{~min}$ on ice with the appropriate dilution of antibodies. For analysis of $\mathrm{CD}^{+}$and $\mathrm{CD}^{+} \mathrm{T}$ cells and their naïve/memory subsets, PBMCs were stained with mouse anti-human CD4, mouse anti-human CD8, mouse anti-human CCR7, and mouse anti-human CD45RA monoclonal antibodies (mAbs). Since the available combination between $\mathrm{mAbs}$ and fluorescent dyes was limited in this multicolor flow cytometry panel, we could not completely compensate the spectral overlap. Therefore, nonlinear gating lines were set by using control samples, as previously reported (16). For analysis of gamma-delta $(\gamma \delta) \mathrm{T}$, natural killer T (NKT), and natural killer (NK) cells, PBMCs were stained with mouse anti-human TCR $\gamma \delta$, mouse anti-human CD3, mouse anti-human CD16, and mouse anti-human CD56 mAbs. For analysis of Treg cells, PBMCs were stained with mouse anti-human CD4, mouse anti-human CD25, and mouse anti-human FoxP3 mAbs using the One Step Staining Human Treg Flow ${ }^{\mathrm{TM}}$ Kit (BioLegend, San Diego, CA, USA). For analysis of granulocytic myeloid-derived suppressor cells (MDSCs), PBMCs were stained with mouse anti-human CD11b, mouse anti-human CD15, and mouse anti-human CD33 mAbs (17). All mAbs were from BioLegend except for the anti-CD15 mAb (BD Biosciences, San Diego, CA, USA). The samples were run on a FACSCanto II analyzer (BD Biosciences), and the frequencies of each of the immune subsets were analyzed using FlowJo ver. 10 software (Tree Star, Ashland, OR, USA).

Immune responses to antigen peptides. To evaluate immune cell function, T-cell responses against viral- or tumor-associated antigen peptides were evaluated by an interferon gamma $(\mathrm{IFN}-\gamma)$ Enzyme-Linked ImmunoSpot (ELISPOT) assay with PBMCs before and after splenectomy in the enrolled patients whose PBMCs were available for analysis. The viral-associated antigen peptide pool consisted of 23 different HLA class I-restricted peptides derived from cytomegalovirus, Epstein-Barr virus, or influenza virus (CEF; Mabtech, Nacka Strand, Sweden). The CEF peptide pool contained 2 HLA-A1-, 3 HLA-A2-, 3 HLA-A3-, 2 HLA-A11-, 1 HLA-A24-, 1 HLA-A68-, 2 HLA-B7-, 4 HLA-B8-, 2 HLA-B27-, 1 HLA-B35-, and 2 HLA-B44-restrcited peptides. The tumor-associated antigen peptide pool consisted of 20 different HLA class I-restricted peptides (KRM-20) as reported previously (18). The KRM-20 peptide pool contained 5 HLA-A2-, 9 HLA-A24-, 3 HLA-A3 supertype-, 1 HLA-A24/A3 supertype-, and 2 HLA-A24/A3 supertype/A26-restrcited peptides. PBMCs $\left(1 \times 10^{5}\right.$ cells/well) were incubated in round 96-well microculture plates (Thermo Fisher Scientific, Rochester, NY, USA) with $200 \mu \mathrm{l}$ of medium (OpTmizer T Cell Expansion SFM; Life Technologies, Carlsbad, CA, USA) containing $10 \%$ fetal bovine serum (MP Biologicals), interleukin 2 (20 $\mathrm{IU} / \mathrm{ml}$; AbD Serotec, Kidlington, UK), and the peptide pools (CEF, $2 \mu \mathrm{g} / \mathrm{ml}$; KRM-20, $10 \mu \mathrm{g} / \mathrm{ml}$ ) for 7 days. After incubation, the cells $\left(1-2 \times 10^{4}\right.$ cells/well $)$ were harvested and tested for their ability to produce IFN- $\gamma$ in response to the corresponding peptide pool (CEF, $2 \mu \mathrm{g} / \mathrm{ml}$; KRM-20, $10 \mu \mathrm{g} / \mathrm{ml}$ ). Antigen-specific IFN- $\gamma$ secretion after $18 \mathrm{~h}$ of incubation was determined by the ELISPOT assay in accordance with the manufacturer's instructions (Mabtech), and spots were counted by an ELISPOT reader (CTL ImmunoSpot S5 Series; Cellular Technology, Ltd., Shaker Heights, OH, USA). Antigen-specific T-cell responses were evaluated by the difference between the numbers of spots produced in response to each corresponding peptide pool and those produced without it.

Statistical analysis. Data are expressed as mean or median with standard deviation. The paired Student's t-tests was used 

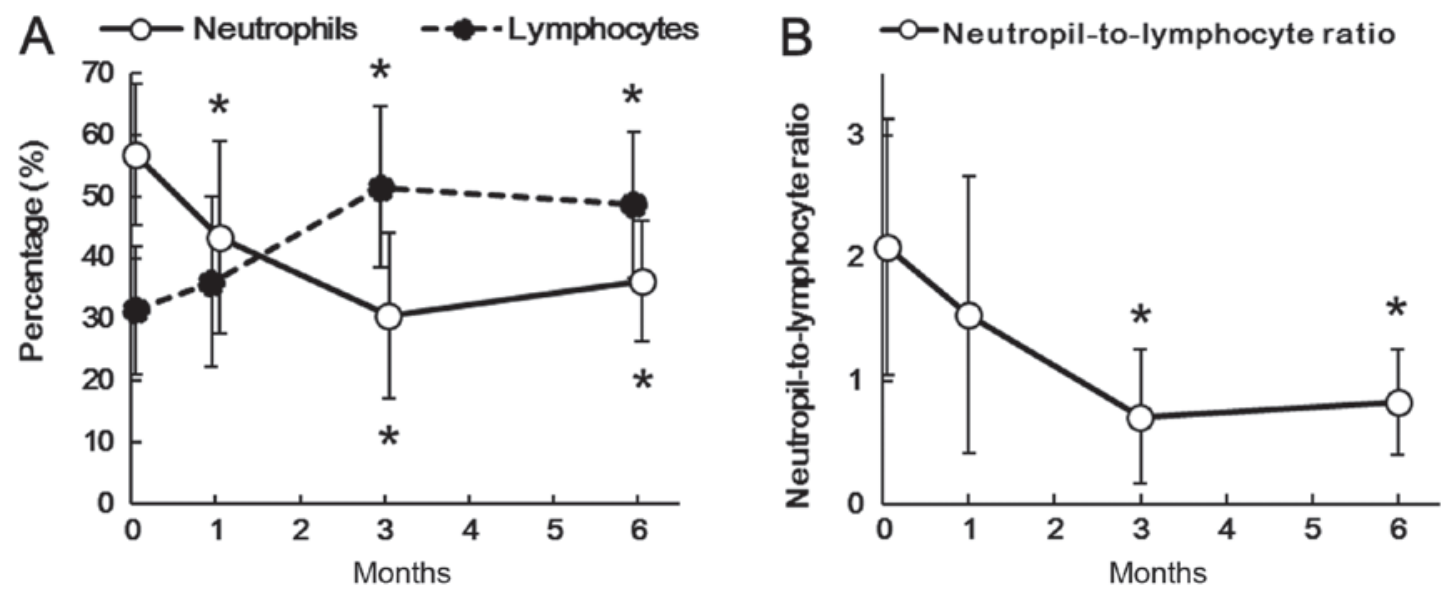

Figure 1. Alterations in lymphocytes and neutrophils following splenectomy. (A) Percentages of lymphocytes and neutrophils in the white blood cell counts before and after splenectomy. (B) Neutrophil-to-lymphocyte ratio before and after splenectomy. The data are presented as the mean \pm standard deviation. The percentages or ratios at the indicated time points after splenectomy were compared with those before splenectomy. ${ }^{*} \mathrm{P}<0.05$ by paired Student's $\mathrm{t}$-test compared with the data before splenectomy.

for comparison of percentages of lymphocytes and neutrophils in the WBC counts, neutrophil-to-lymphocyte ratios and immune cell phenotypes determined by flow cytometry. Since these analyses were exploratory, but not confirmatory, paired Student's t-tests was employed without considering adjustment of multiplicity. The Wilcoxon signed rank test was used for comparison of spot numbers of antigen-specific $\mathrm{T}$ cells determined by ELISPOT assay. A two-sided significance level of 5\% was considered statistically significant in all analyses. Statistical analyses were performed using SAS software version 9.4 (SAS Institute, Cary, NC).

\section{Results}

Clinical outcomes. The average weight of the excised spleen was $522 \pm 211 \mathrm{~g}$. The average blood loss volume was $82 \pm 187 \mathrm{ml}$, and the average operation time was $235 \pm 74 \mathrm{~min}$. Postoperative complications were portal thrombosis $(n=1)$, ascites $(n=1)$, bacterial colitis $(n=1)$, and fever $(n=1)$. Portal thrombosis was treated with anticoagulants. Bacterial infection and ascites were successfully treated with antibiotics and diuretics, respectively. No patients had fatal complications. Patients were discharged at $14 \pm 2.6$ days.

The average platelet count before splenectomy was $4.9 \pm 1.6 \times 10^{4} / \mathrm{mm}^{3}$, and the average WBC count was $2633 \pm 947 / \mathrm{mm}^{3}$. Although the neutrophil count was significantly higher only at 1 month after splenectomy $(\mathrm{P}=0.039)$, the lymphocyte count remained at higher levels at 1 month $(\mathrm{P}=0.004), 3$ months $(\mathrm{P}<0.001)$, and 6 months $(\mathrm{P}<0.001)$. The percentage of neutrophils in WBC was significantly higher than that of lymphocytes in WBC before splenectomy $(\mathrm{P}<0.05)$. In contrast to a significant decrease in the percentages of neutrophils in WBC at 1 month $(\mathrm{P}=0.033), 3$ months $(\mathrm{P}<0.001)$, and 6 months $(\mathrm{P}=0.001)$ after splenectomy, those of lymphocytes in WBC significantly increased at 3 months $(\mathrm{P}<0.001)$ and 6 months $(\mathrm{P}=0.005$; Fig. 1A). The NLR significantly decreased at 3 months $(\mathrm{P}<0.001)$ and 6 months $(\mathrm{P}=0.008$; Fig. 1B).

Changes in $\mathrm{CD}^{+}$and $C D 8^{+} T$ cells and their nä̈ve/memory subsets. Fig. 2A shows a representative flow cytometry profile of $\mathrm{CD}^{+} \mathrm{T}$ cells, $\mathrm{CD} 8^{+} \mathrm{T}$ cells, and their naïve/memory subsets in PBMCs before and after splenectomy. As shown in Fig. 2B, the frequency of $\mathrm{CD}^{+} \mathrm{T}$ cells significantly decreased at 1 month $(\mathrm{P}=0.003), 3$ months $(\mathrm{P}=0.001)$, and 6 months $(\mathrm{P}=0.016)$ after splenectomy, while that of $\mathrm{CD}^{+}$ $\mathrm{T}$ cells significantly increased at 3 months $(\mathrm{P}=0.004)$ and 6 months $(\mathrm{P}=0.014)$. In addition, the frequencies of the naïve $\left(\mathrm{CCR}^{+} \mathrm{CD}^{2} 5 \mathrm{RA}^{+}\right)$and central memory $\left(\mathrm{CCR} 7^{+} \mathrm{CD} 45 \mathrm{RA}^{-}\right)$ subset of $\mathrm{CD}^{+} \mathrm{T}$ cells significantly decreased at 1 month $(\mathrm{P}<0.001$ and $\mathrm{P}=0.022$, respectively), 3 months $(\mathrm{P}=0.001$ and $\mathrm{P}=0.012$, respectively), and 6 months $(\mathrm{P}<0.001$ and $\mathrm{P}=0.023$, respectively) after splenectomy. In contrast, that of the effector memory subset (CCR7-CD45RA') significantly increased at 1 month $(\mathrm{P}=0.001), 3$ months $(\mathrm{P}<0.001)$, and 6 months $(\mathrm{P}=0.001$; Fig. 2C).

Similarly, in $\mathrm{CD}^{+} \mathrm{T}$ cells, the frequencies of the naïve $\left(\mathrm{CCR}^{+} \mathrm{CD} 45 \mathrm{RA}^{+}\right)$and central memory $\left(\mathrm{CCR} 7^{+} \mathrm{CD} 45 \mathrm{RA}^{-}\right)$ subset significantly decreased at 1 month $(\mathrm{P}=0.007$ and $\mathrm{P}=0.017$, respectively), 3 months $(\mathrm{P}=0.010$ and $\mathrm{P}=0.018$, respectively), and 6 months $(\mathrm{P}=0.008$ and $\mathrm{P}=0.008$, respectively) after splenectomy, whereas that of the effector memory subset (CCR7 ${ }^{-}$CD45RA ${ }^{-}$) significantly increased after 1 month $(\mathrm{P}=0.003), 3$ months $(\mathrm{P}=0.017)$, and 6 months $(\mathrm{P}=0.011$; Fig. 2D).

Changes in $\gamma \delta T, N K T$, and NK cells. We also investigated the frequencies of $\gamma \delta \mathrm{T}, \mathrm{NKT}$, and NK cells among PBMCs before and after splenectomy. Fig. 3A shows a representative flow cytometry profile of $\gamma \delta \mathrm{T}$, NKT and NK cells. As shown in Fig. 3B, the frequency of $\gamma \delta \mathrm{T}$ cells $\left(\mathrm{CD} 3^{+} \mathrm{TCR}\right.$ $\left.\gamma \delta^{+}\right)$significantly increased at 1 month $(\mathrm{P}=0.039)$ and 3 months $(\mathrm{P}=0.008)$ after splenectomy. In the same manner, the frequency of NKT cells $\left(\mathrm{CD}^{+} \mathrm{CD}^{+} 6^{+}\right)$tended to increase after 1 month $(\mathrm{P}=0.064)$ and 3 months $(\mathrm{P}=0.007$; Fig. $3 \mathrm{C})$. However, NK cells $\left(\mathrm{CD}^{-}{ }^{-} 56^{+}\right)$showed a significant increase after 1 month $(\mathrm{P}=0.010)$, but not at any other time points ( 3 months, $\mathrm{P}=0.134 ; 6$ months, $\mathrm{P}=0.210$; Fig. $3 \mathrm{D}$ ). The frequency of the CD56 ${ }^{\mathrm{dim}} \mathrm{CD} 16^{+} \mathrm{NK}$ cell subset tended to increase at 1 month $(\mathrm{P}=0.052), 3$ months $(\mathrm{P}=0.017)$, and 6 months $(P=0.070)$ after splenectomy, whereas that of the 
A

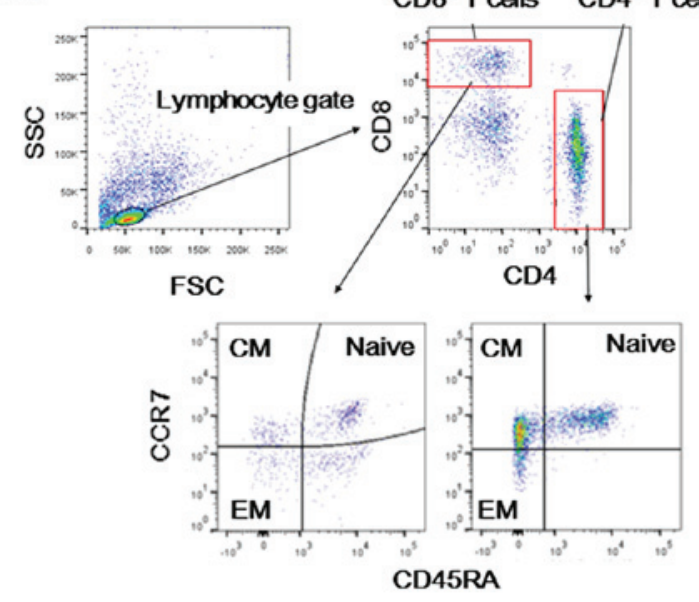

B

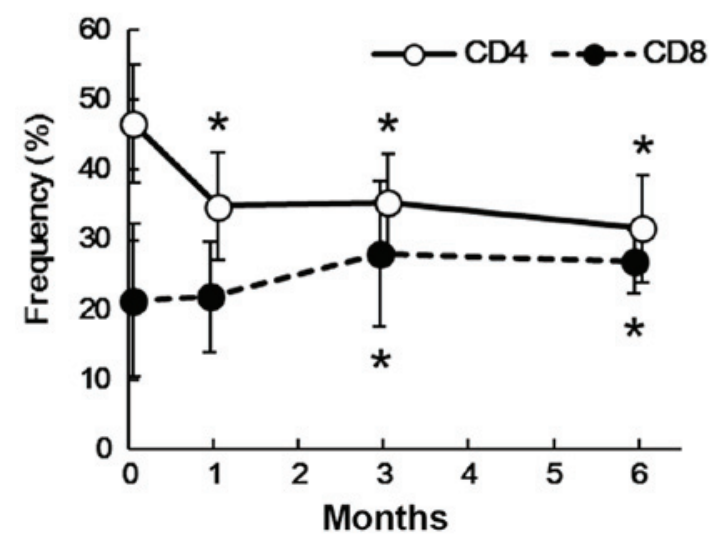

C $\quad$ CD4 $^{+}$T cells

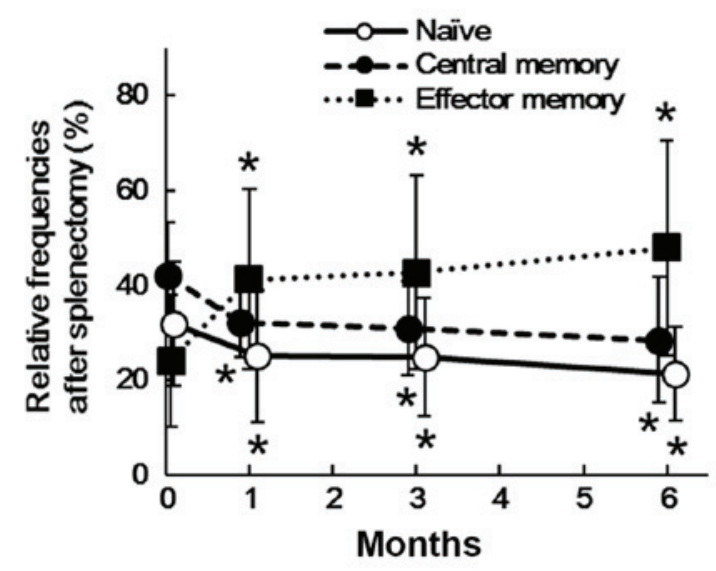

D CD8 ${ }^{+} \mathrm{T}$ cells

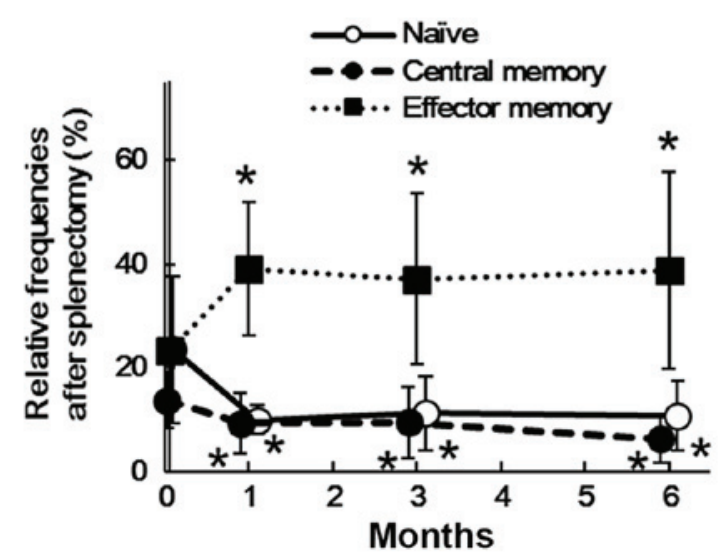

Figure 2. Alterations in $\mathrm{CD}^{+}$and $\mathrm{CD}^{+} \mathrm{T}$ cells and their naïve/memory subsets following splenectomy. (A) Representative flow cytometry profile of naïve/memory subsets in $\mathrm{CD}^{+}$and $\mathrm{CD}^{+} \mathrm{T}$ cells. (B) Frequencies of $\mathrm{CD} 4^{+}$and $\mathrm{CD} 8^{+} \mathrm{T}$ cells before and after splenectomy. Frequencies of naïve/memory subsets in (C) $\mathrm{CD}^{+} \mathrm{T}$ cells or (D) $\mathrm{CD}^{+} \mathrm{T}$ cells before and after splenectomy. The data are presented as the mean \pm standard deviation. The frequencies at the indicated time points after splenectomy were compared with those before splenectomy in each of the naïve/memory subsets. * $\mathrm{P}<0.05$ by paired Student's t-test compared with the data before splenectomy. CM, central memory; EM, effector memory; CD, cluster of differentiation; CCR7, C-C chemokine receptor type 7; SSC, side scatter; FSC, forward scatter.

CD56 ${ }^{\text {bright }} \mathrm{CD} 16^{\mathrm{dim} /-} \mathrm{NK}$ cell subset tended to decrease after 1 month $(\mathrm{P}=0.023), 3$ months $(\mathrm{P}=0.068)$, and 6 months $(\mathrm{P}=0.069$; Fig. 3E). We observed significant changes in $\gamma \delta \mathrm{T}$, NKT, and NK cells only at the earlier two time points (1 and 3 months), suggesting that they might represent a transient, but not continuous, response to splenectomy.

Changes in Treg cells and MDSC. The frequencies of inhibitory immune cell subsets, including Treg cells and MDSCs, were further examined in PBMCs before and after splenectomy. Fig. 4A shows a representative flow cytometry profile of Treg cells. As shown in Fig. 4B, the frequency of Treg cells $\left(\mathrm{CD} 4^{+} \mathrm{CD} 25^{+} \mathrm{FoxP} 3^{+}\right)$among PBMCs transiently decreased 3 months $(\mathrm{P}=0.045)$ after splenectomy, but not at the other time points ( 1 month, $\mathrm{P}=0.782 ; 6$ months, $\mathrm{P}=0.416)$. Fig. 4C shows a representative flow cytometry profile of granulocytic MDSCs. As shown in Fig. 4D, the frequency of granulocytic MDSCs $\left(\mathrm{CD} 11 \mathrm{~b}^{+} \mathrm{CD} 15^{+} \mathrm{CD} 33^{+}\right)$was significantly lower at 3 months $(\mathrm{P}=0.022)$ and 6 months $(\mathrm{P}=0.045)$ after splenectomy. In contrast, the frequency of monocytic MDSCs (CD14 ${ }^{+} \mathrm{HLA}^{-D R^{-/ l o w}}$ ) was not significantly affected (data not shown).
Evaluation of T-cell responses to viral-and tumor-associated antigens. To evaluate the effects of splenectomy on immune function, we examined T-cell responses to viral-associated $(n=8)$ and tumor-associated $(n=5)$ antigens using an IFN- $\gamma$ ELISPOT assay with PBMCs before and after splenectomy. Fig. 5A and $\mathrm{B}$ show representative results of the assay in response to both viral- and tumor-associated antigens. In five of eight patients with liver cirrhosis, PBMCs after splenectomy showed higher numbers of IFN- $\gamma$-producing cells after stimulation with the viral-associated antigen peptide pool (CEF) compared with those before splenectomy. As shown in Fig. 5C, the spot numbers of CEF-specific cells after 6 months of splenectomy were significantly higher than those before splenectomy $(\mathrm{P}=0.031)$. In addition, when $\mathrm{PBMCs}$ were stimulated with the tumor-associated antigen peptide pool (KRM-20), more IFN- $\gamma$-producing T cells were detected after splenectomy in two of five patients with cirrhosis. As shown in Fig. 5C, the spot numbers of KRM-20-specific cells after 6 months of splenectomy tended to be higher than those before splenectomy, although not statistically significant $(\mathrm{P}=0.125)$, possibly due to the small sample size and the high standard deviation. 
A
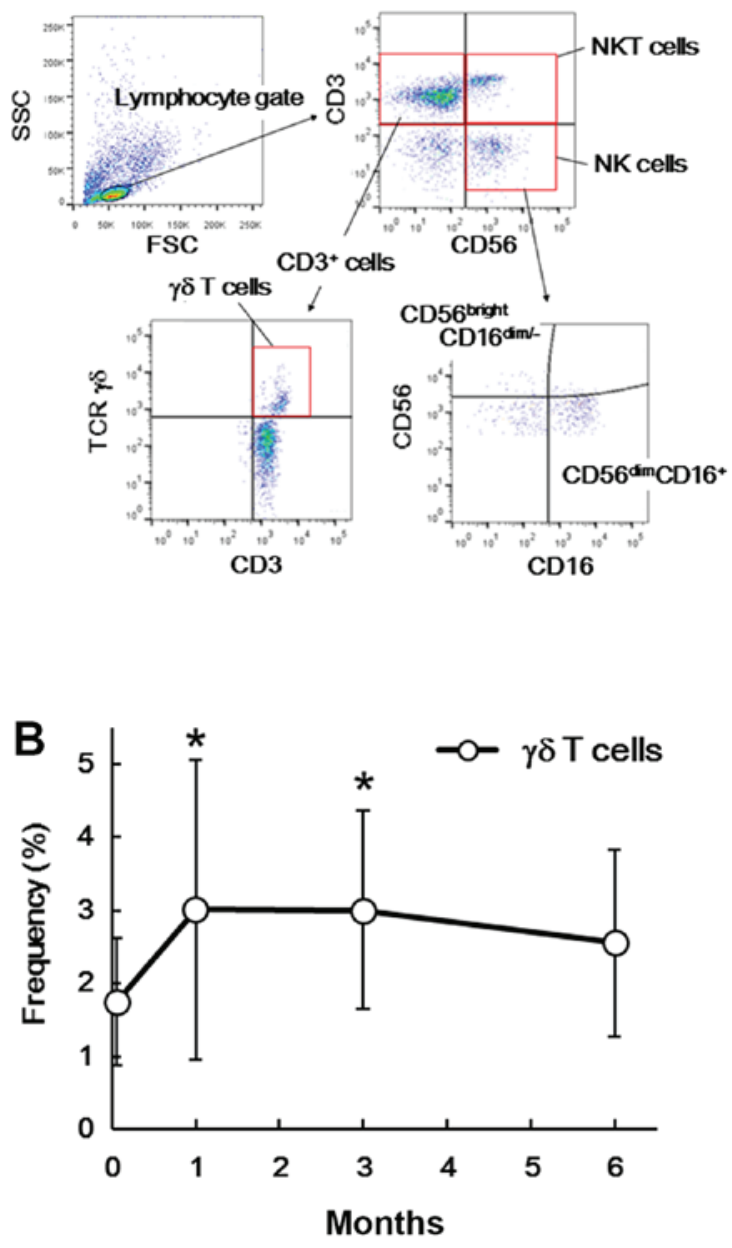

C
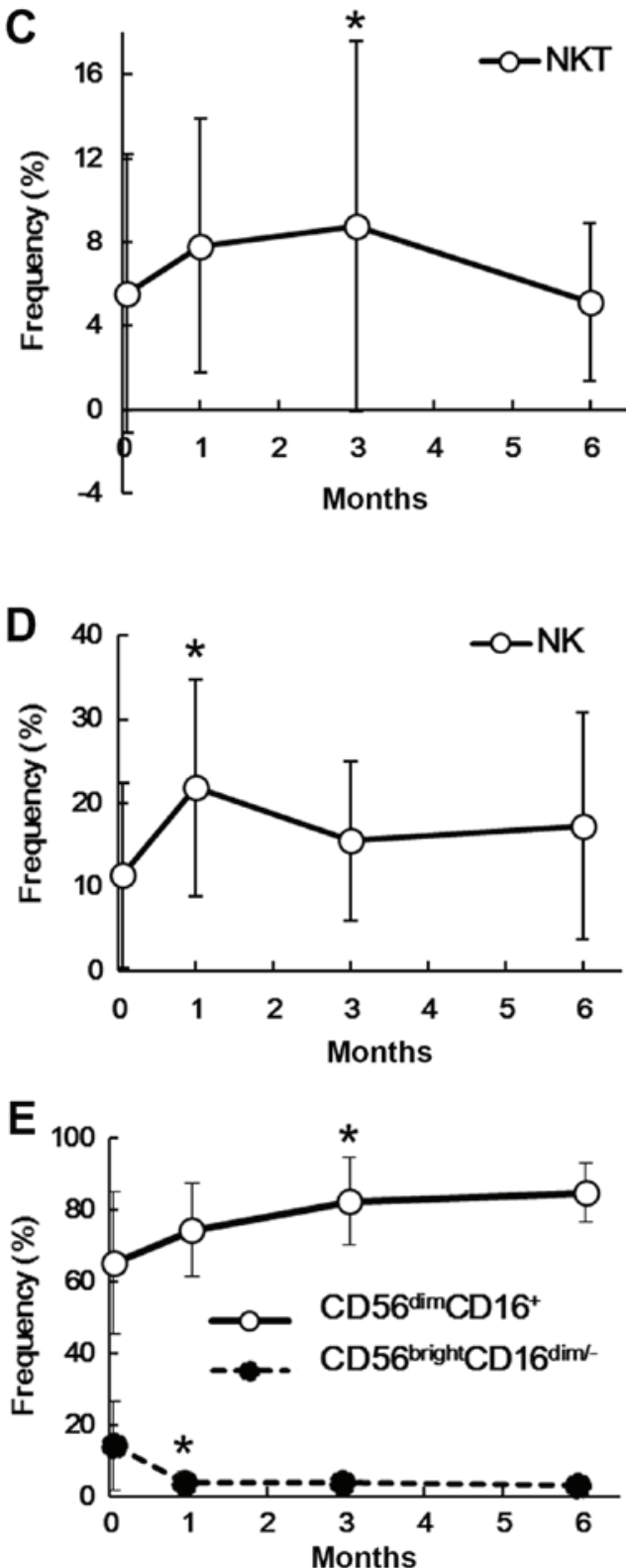

Figure 3. Alterations in $\gamma \delta$ T, NKT and NK cells after splenectomy. (A) Representative flow cytometry profile of $\gamma \delta$ T, NKT and NK cells. Frequencies of (B) $\gamma \delta$ T cells, (C) NKT cells, (D) NK cells or (E) NK cell subsets defined by CD16 and CD56 expressions before and after splenectomy. Data are presented as the mean \pm standard deviation. The frequencies at the indicated time points after splenectomy were compared with those before splenectomy. "P<0.05 by paired Student's t-test compared with the data before splenectomy. NKT, natural killer T; NK, natural killer; CD, cluster of differentiation; SSC, side scatter; FSC, forward scatter; TCR, T-cell receptor.

\section{Discussion}

The current study demonstrated that splenectomy significantly increased the frequencies of immune cells with effector properties such as $\mathrm{CD} 8^{+} \mathrm{T}$ cells, $\gamma \delta \mathrm{T}$ cells, NKT cells, and NK cells, but significantly decreased those with suppressive properties such as Treg cells and MDSCs. In addition, the immune responses against viral- and tumor-associated antigens were augmented after splenectomy. These findings suggest that splenectomy might ameliorate the impaired immune status in cirrhotic patients with hypersplenism.

The NLR is one of the markers used to identify systemic inflammation, which is associated with the development, progression, and prognosis of various benign and malignant diseases. A higher NLR reflects increased production and secretion of pro-inflammatory cytokines and vascular endothelial growth factor by neutrophils in the circulation, resulting in vascular invasion, seeding, and growth of malignant cells $(13,14,19,20)$. For example, an elevated NLR has been reported to correlate with the tumor burden, recurrence, and survival in patients with colorectal cancer, colorectal liver metastasis, HCC, gastric cancer, renal cancer, and pancreatic cancer $(13,14,19-21)$. The NLR has also been found to reflect the severity of other diseases, including sepsis, cardiovascular abnormalities, and diabetes mellitus (22). The present study showed that the NLR was significantly lower at 3 and 6 months after splenectomy. Similarly, reduction of the NLR, which was correlated with better prognosis, was observed after splenectomy in our previous study of patients with HCC (7). 
A
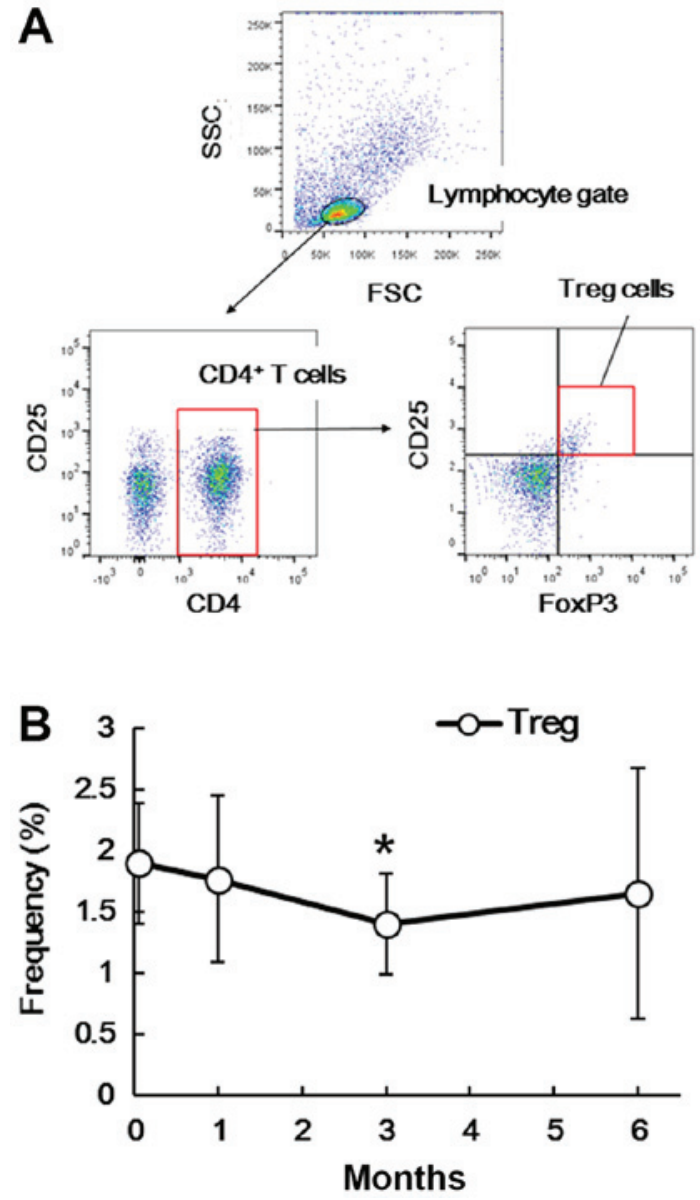
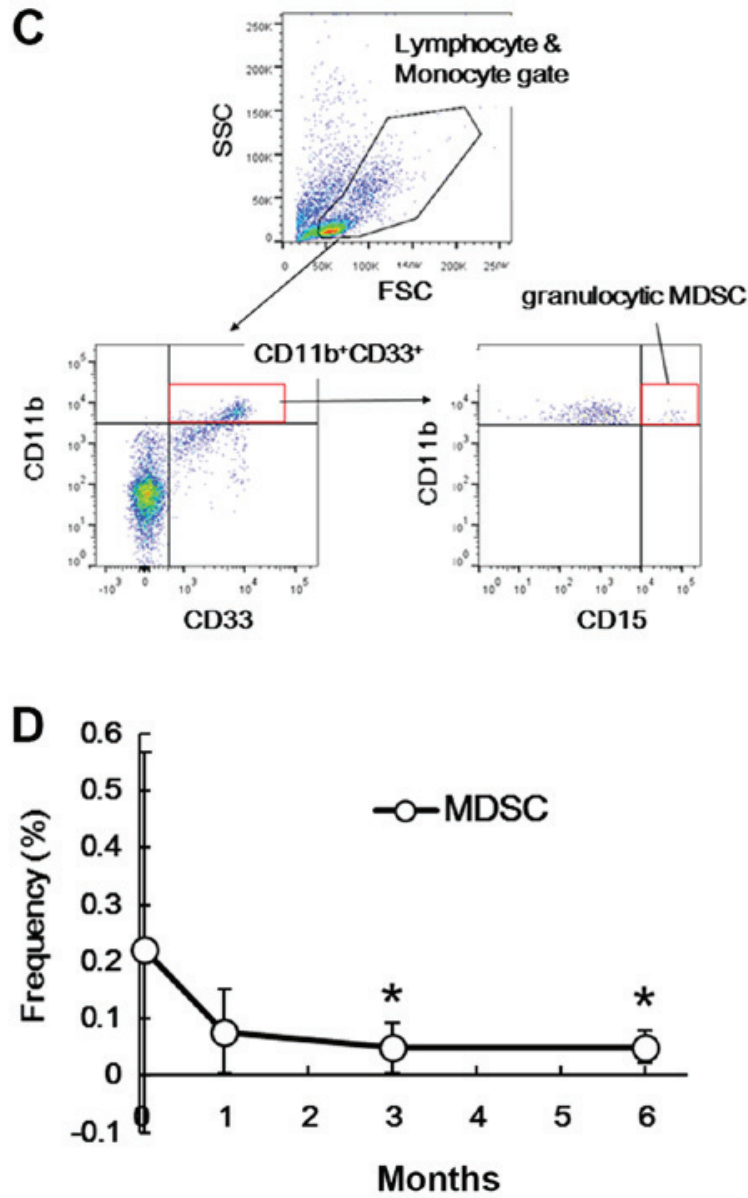

Figure 4. Alterations in Treg cells and MDSCs after splenectomy. (A) Representative flow cytometry profile of Treg $\left(\mathrm{CD} 4^{+} \mathrm{CD} 25^{+} \mathrm{FoxP} 3^{+}\right)$cells. (B) Frequencies of Treg cells before and after splenectomy. (C) Representative flow cytometry profile of granulocytic MDSCs $\left(\mathrm{CD} 11 \mathrm{~b}^{+} \mathrm{CD} 15^{+} \mathrm{CD} 33^{+}\right)$. (D) Frequencies of granulocytic MDSCs before and after splenectomy. Data are presented as the mean \pm standard deviation. The frequencies at the indicated time points after splenectomy were compared with those before splenectomy. " $\mathrm{P}<0.05$ by paired Student's t-test compared with the data before splenectomy. Treg, regulatory T; MDSCs, myeloid-derived suppressor cells; CD, cluster of differentiation; FoxP3, forkhead box protein P3; SSC, side scatter; FSC, forward scatter.

Patients with cirrhosis have a higher $\mathrm{CD} 4^{+} / \mathrm{CD} 8^{+} \mathrm{T}$ cell ratio because of an increase in $\mathrm{CD} 4^{+} \mathrm{T}$ cell frequency together with a decrease in $\mathrm{CD} 8^{+} \mathrm{T}$ cell frequency (3). Since $\mathrm{CD} 8^{+}$ $\mathrm{T}$ cells play crucial roles in anti-infection and anti-tumor immune responses, patients with liver cirrhosis are considered to be immunocompromised in part due to reduced CD8 cells, which might lead to higher incidences of bacterial infection and HCC development/recurrence $(3,4)$. The current study demonstrated that splenectomy lowered the $\mathrm{CD} 4^{+} / \mathrm{CD} 8^{+} \mathrm{T}$-cell ratio by decreasing the $\mathrm{CD} 4^{+}$T-cell frequency and increasing the $\mathrm{CD} 8^{+} \mathrm{T}$-cell frequency, which may potentially enhance the anti-infection and anti-tumor immune responses. In addition, we detected an increase in effector memory T-cell subsets and a reduction in naïve and central memory subsets after splenectomy. Naïve T cells initiate immune responses to new antigens, while memory $\mathrm{T}$ cells (central memory and effector memory cells) respond to previously encountered antigens (23). Central memory cells are restricted to the lymphoid tissue and blood, whereas effector memory cells broadly migrate between peripheral tissues, blood, and the spleen, and provide immediate protection against pathogens (24). Such changes in naïve/memory T-cell subsets in this study might have resulted from accelerated antigen-specific immune responses after splenectomy $(23,25,26)$. Indeed, in the current study,
T-cell-mediated IFN- $\gamma$ production in response to viral- and tumor-associated antigens was shown to increase after splenectomy in some patients with cirrhosis. Similarly, it has been suggested that splenectomy in patients with cirrhosis might improve their impaired immune status by increasing IFN- $\gamma$ production and reducing programmed cell death protein 1 (PD-1)-expression in peripheral CD4 T cells $(27,28)$.

This is the first study to show a decrease in MDSCs after splenectomy in patients with cirrhosis. Recent studies have shown that MDSCs are closely associated with suppressive immune conditions (29) and that a high MDSC count before treatment is a negative prognostic factor for patients with HCC undergoing hepatic arterial infusion chemotherapy (30). In tumor-bearing animal models, immature myeloid cells, including MDSCs, were found to accumulate in the spleen, the removal of which inhibited the growth and progression of liver cancer and prolonged animal survival (31). Because MDSCs also inhibit cytotoxic T-cell activation $(25,26,31)$, the reduced number of MDSCs in our patients after splenectomy might enhance immune competence.

The current study also demonstrated for the first time that $\mathrm{CD} 4{ }^{+} \mathrm{CD} 25^{+} \mathrm{FoxP}^{+}{ }^{+}$Treg cells decreased after splenectomy in the peripheral circulation of patients with cirrhosis. Treg cells are another subset of immune suppressors that play an 
A

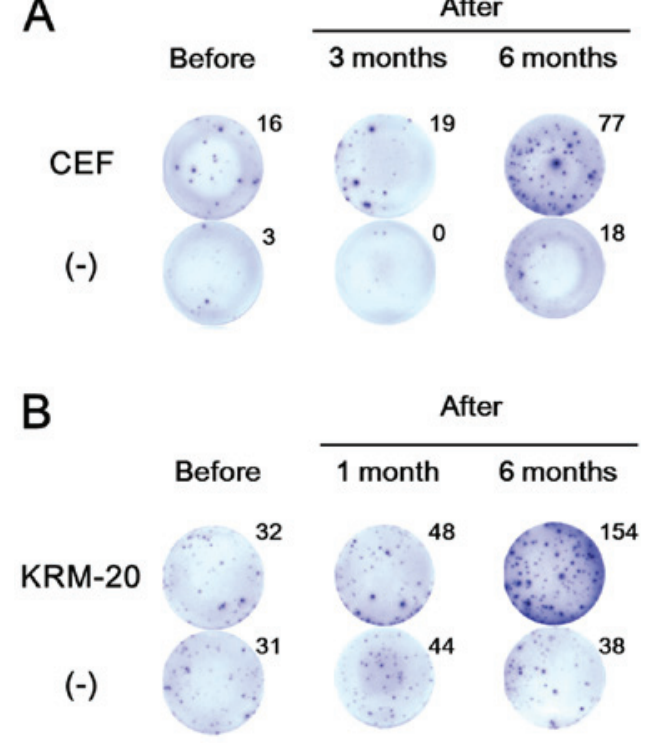

C

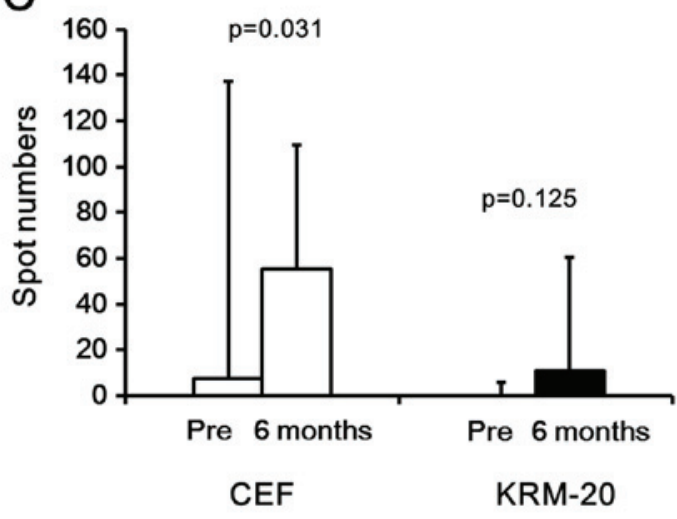

Figure 5. T-cell responses to viral- and tumor-associated antigens. T-cell responses to viral- and tumor-associated antigens were evaluated by IFN- $\gamma$ ELISPOT assay with PBMCs before and after splenectomy. (A) Representative result of the IFN- $\gamma$ ELISPOT assay with PBMCs (1x10 4 cells/well) stimulated with or without the viral-associated CEF peptide pool in a patient with cirrhosis before and after splenectomy. (B) Representative result of IFN- $\gamma$ ELISPOT assay with PBMCs $\left(1.3 \times 10^{4}\right.$ cells/well) stimulated with or without the tumor-associated KRM-20 peptide pool in a patient with cirrhosis before and after splenectomy. The numbers of spots produced by antigen-specific T-cell responses are shown. (C) Spot numbers of CEF- or KRM-20-specific cells after 6 months of splenectomy were compared with those before splenectomy by the Wilcoxon signed rank test. Data are presented as the median with standard deviation. IFN- $\gamma$, interferon- $\gamma$; PBMCs, peripheral blood mononuclear cells.

important role in the development and progression of various diseases such as autoimmune disease, viral infection, and cancer (29). In a previous study, the frequency of Treg cells was elevated in patients with $\mathrm{HCV}^{+}$liver cirrhosis (32). A higher frequency of Treg cells was shown to be significantly associated with enhanced tumor growth of HCC in patients undergoing intra-arterial chemotherapy (33). The spleen is also reportedly a major source of Treg cells in patients with splenomegaly (34). MDSCs, the numbers of which decreased after splenectomy in this study, promote de novo development and induction of Treg cells (29). Considering all of these findings, splenectomy appears to enhance the immune response through reduction of Treg cells and MDSCs in the spleen and peripheral blood.

In contrast, NK cells play an important role in anti-viral and anti-tumor defenses. NK cells perform various effector functions, including production of IFN- $\gamma$, activation of tumor antigen-specific $\mathrm{CD} 8^{+} \mathrm{T}$ cells, and initiation of perforin-mediated cytolysis of tumor cells $(35,36)$. Other researchers have reported that in patients with $\mathrm{HCV}^{+}$liver cirrhosis, $\mathrm{NK}$ cells decreased in number and were correlated with HCC development (37), and that HCV downregulated NK cell function via viral serine protease NS3 (38). In the current study, the frequency of NK cells significantly increased 1 month after splenectomy. In particular, the number of cells in the CD56 $\mathrm{dim}$ NK cell subset, which exhibited more powerful cytotoxic activity than CD56 ${ }^{\text {bright }} \mathrm{NK}$ cells (39), was significantly elevated after splenectomy. Splenectomy in HCV-positive patients with cirrhosis augmented the activity of NK cells (36). A significant increase in both the percentage and activity of NK cells after splenectomy has also been reported by other researchers (40). Because MDSCs reportedly suppress the production of IFN- $\gamma$ by NK cells (41), it is possible that reduction of MDSCs after splenectomy may increase the NK cell number and function to augment protective immunity.

Recently, oral thrombopoietin receptor agonists have been reported to stimulate thrombopoiesis, and potentially improve pancytopenia in cirrhotic patients $(42,43)$. They transiently increase platelet counts for a limited period $(42,43)$, while splenectomy in cirrhotic patients improve hypersplenism, including increase of platelet and white blood cell counts, for a long period $(7,8)$. In addition, splenectomy not only has the clinical benefits, such as improvement of liver function and reduction of portal venous pressure (7-11), but also may contribute to immunological benefits, based on our study and others $(27,28)$. It would be interesting to examine immune status after treatment with oral thrombopoietin receptor agonists and compare it with that after splenectomy in cirrhotic patients.

Partial splenic embolization (PSE) via catheter intervention is also known to be an effective alternative to splenectomy that is less invasive than surgery. Interestingly, Matsukiyo et al recently reported that PSE not only improve leukopenia and thrombocytopenia but also induce activation of $\mathrm{CD}^{+} \mathrm{T}$ cells, including Th1 and Th2 cells, in patients with cirrhosis and thrombocytopenia (44). Because the current study did not address Th1 and Th2 cytokine expression and their balance in $\mathrm{CD}^{+} \mathrm{T}$ cells, it would be interesting to examine them before and after splenectomy and compare them with those after PSE in cirrhotic patients in future studies. Matsukiyo et al also demonstrated that Treg cells, which were identified as $\mathrm{CD} 4{ }^{+} \mathrm{CD} 25^{\text {high }} \mathrm{CD} 127^{\text {low }}$, did not significantly change after PSE (44), whereas we showed that Treg cells, which were identified as $\mathrm{CD} 4{ }^{+} \mathrm{CD} 25^{+} \mathrm{FoxP} 3{ }^{+}$, decreased after splenectomy in patients with cirrhosis. Such discrepancy might be explained by the different definition of Treg cells, as previously reported (45). 
In summary, the current study suggested that splenectomy might ameliorate the impaired immune status of patients with cirrhosis, possibly by reducing suppressive cell fractions and enhancing the effector cell population and function. To our knowledge, this is the first study to comprehensively examine the effects of splenectomy on the NLR as well as the immunological phenotypes and responses in peripheral blood. However, this study has several limitations. First, this was a small study comprising patients with different disease states. Second, although changes in the immune cell phenotypes were precisely characterized, the immune functions of each cell subset were not examined in detail. Third, the enrolled patients were followed only for a limited period of time after splenectomy. Further studies with more patients and longer follow-ups are required.

\section{Acknowledgements}

The authors would like to thank Ms Yuri Kasama-Kawaguchi (Kurume University, Kurume, Japan) for her technical assistance.

\section{Funding}

No funding was received.

\section{Availability of data and materials}

The datasets used and/or analyzed during the present study are available from the corresponding author on reasonable request.

\section{Authors' contributions}

TO and TS planned and designed the study. YH, TO, TS and TY performed the experiments and data analysis. YH, TO and $\mathrm{KO}$ treated the patients and acquired the clinical data and samples. KI, HT and KO provided scientific advice and interpreted the data. YH, TO and TS interpreted the data and drafted the manuscript. All authors read and approved the final manuscript.

\section{Ethical approval and consent to participate}

The present study was conducted in accordance with the provisions of the Declaration of Helsinki and was approved by the Institutional Review Board at Kurume University Hospital (Kurume, Japan). Before surgery, possible undesirable outcomes were explained to all patients involved in the study, and written informed consent was obtained from them.

\section{Patient consent for publication}

Not applicable.

\section{Competing interests}

Kyogo Itoh has stock ownership of BrightPath Biotherapeutics Co., Ltd., and received research funding from Taiho Pharmaceutical Co., Ltd. Takuto Yamashita is an employee of BrightPath Biotherapeutics Co., Ltd. The other authors declare that they have no competing interests.

\section{References}

1. Planas R, Ballesté B, Alvarez MA, Rivera M, Montoliu S, Galeras JA, Santos J, Coll S, Morillas RM and Solà R: Natural history of decompensated hepatitis $\mathrm{C}$ virus-related cirrhosis. A study of 200 patients. J Hepatol 40: 823-830, 2004.

2. Borzio M, Salerno F, Piantoni L, Cazzaniga M, Angeli P, Bissoli F, Boccia S, Colloredo-Mels G, Corigliano P, Fornaciari G, et al: Bacterial infection in patients with advanced cirrhosis: A multicentre prospective study. Dig Liver Dis 33: 41-48, 2001.

3. Nomura Y, Kage M, Ogata T, Kondou R, Kinoshita H, Ohshima K and Yano $\mathrm{H}$ : Influence of splenectomy in patients with liver cirrhosis and hypersplenism. Hepatol Res 44: E100-E109, 2014.

4. Wada Y, Nakashima O, Kutami R, Yamamoto O and Kojiro M Clinicopathological study on hepatocellular carcinoma with lymphocytic infiltration. Hepatology 27: 407-414, 1998.

5. Okabayashi T and Hanazaki K: Overwhelming postsplenectomy infection syndrome in adults-a clinically preventable disease. World J Gastroenterol 14: 176-179, 2008.

6. Kawaguchi T, Kuromatsu R, Ide T, Taniguchi E, Itou M, Sakata M, Abe M, Sumie S and Sata M: Thrombocytopenia, an important interfering factor of antiviral therapy and hepatocellular carcinoma treatment for chronic liver diseases. Kurume Med J 56: 9-15, 2009.

7. Ogata T, Okuda K, Sato T, Hirakawa Y, Yasunaga M, Horiuchi H, Nomura Y, Kage M, Ide T, Kuromatsu R, et al: Long-term outcome of splenectomy in advanced cirrhotic patients with hepatocellular carcinoma and thrombocytopenia. Kurume Med J 60: 37-45, 2013.

8. Hashizume M, Tomikawa M, Akahoshi T, Tanoue K, Gotoh N, Konishi K, Okita K, Tsutsumi N, Shimabukuro R, Yamaguchi S and Sugimachi K: Laparoscopic splenectomy for portal hypertension. Hepatogastroenterology 49: 847-852, 2002.

9. Anegawa G, Kawanaka H, Uehara H, Akahoshi T, Konishi K, Yoshida D, Kinjo N, Hashimoto N, Tomikawa M, Hashizume M and Maehara Y: Effect of laparoscopic splenectomy on portal hypertensive gastropathy in cirrhotic patients with portal hypertension. J Gastroenterol Hepatol 24: 1554-1558, 2009.

10. Hu K, Lei P, Yao Z, Wang C, Wang Q, Xu S, Xiong Z, Huang H, $\mathrm{Xu}$ R, Deng $M$ and Maehara Y: Laparoscopic RFA with splenectomy for hepatocellular carcinoma. World J Surg Oncol 14: 196, 2016.

11. Yoshizumi T, Taketomi A, Soejima Y, Ikegami T, Uchiyama H, Kayashima H, Harada N, Yamashita Y, Kawanaka H, Nishizak T and Maehara Y: The beneficial role of simultaneous splenectomy in living donor liver transplantation in patients with small-for-size graft. Transpl Int 21: 833-842, 2008.

12. Zhang XY, Li C, Wen TF, Yan LN, Li B, Yang JY, Wang WT and Jiang L: Synchronous splenectomy and hepatectomy for patients with hepatocellular carcinoma and hypersplenism: A casecontrol study. World J Gastroenterol 21: 2358-2366, 2015.

13. Halazun KJ, Hardy MA, Rana AA, Woodland DC IV, Luyten EJ, Mahadev S, Witkowski P, Siegel AB, BrownRS Jr and Emond JC: Negative impact of neutrophil-lymphocyte ratio on outcome after liver transplantation for hepatocellular carcinoma. Ann Surg 250: 141-151, 2009.

14. Aino H, Sumie S, Niizeki T, Kuromatsu R, Tajiri N, Nakano M, Satani M, Okamura S, Shimose S, Miyahara K and Torimura T: The systemic inflammatory response as a prognostic factor for advanced hepatocellular carcinoma with extrahepatic metastasis. Mol Clin Oncol 5: 83-88, 2016.

15. Kinjo N, Kawanaka H, Akahoshi T, Tomikawa M, Yamashita N, Konishi K, Tanoue K, Shirabe K, Hashizume M and Maehara Y: Risk factors for portal venous thrombosis after splenectomy in patients with cirrhosis and portal hypertension. Br J Surg 97: 910-916, 2010.

16. Roederer M: Spectral compensation for flow cytometry: Visualization artifacts, limitations and caveats. Cytometry 45: 194-205, 2001.

17. Dumitru CA, Moses K, Trellakis S, Lang S and Brandau S: Neutrophils and granulocytic myeloid-derived suppressor cells: Immunophenotyping, cell biology and clinical relevance in human oncology. Cancer Immunol Immunother 61: 1155-1167, 2012.

18. Noguchi M, Arai G, Matsumoto K, Naito S, Moriya F, Suekane S, Komatsu N, Matsueda S, Sasada T, Yamada A, et al: Phase I trial of a cancer vaccine consisting of 20 mixed peptides in patients with castration-resistant prostate cancer: Dose-related immune boosting and suppression. Cancer Immunol Immunother 64: 493-505, 2015. 
19. Tang H, Li B, Zhang A, Lu W, Xiang C and Dong J: Prognostic significance of neutrophil-to-lymphocyte ratio in colorectal liver metastasis: A systematic review and meta-analysis. PLoS One 18: e0159447, 2016.

20. Yang JJ, Hu ZG, Shi WX, Deng T, He SQ and Yuan SG: Prognostic significance of neutrophil to lymphocyte ratio in pancreatic cancer: A meta-analysis. World J Gastroenterol 7 : 2807-2815, 2015.

21. Min KW, Kwon MJ, Kim DH, Son BK, Kim EK, Oh YH and Wi YC: Persistent elevation of postoperative neutrophil-to-lymphocyte ratio: A better predictor of survival in gastric cancer than elevated preoperative neutrophil-to-lymphocyte ratio. Sci Rep 25: 13967, 2017.

22. Mozos I, Malainer C, Horbańczuk J, Gug C, Stoian D, Luca CT and Atanasov AG: Inflammatory markers for arterial stiffness in cardiovascular diseases. Front Immunol 8: 1058, 2017.

23. Mueller SN, Gebhardt T, Carbone FR and Heath WR: Memory T cell subsets, migration patterns and tissue residence. Annu Rev Immunol 31: 137-161, 2013

24. Groot F, van Capel TM, Schuitemaker J, Berkhout B and de Jong EC: Differential susceptibility of naïve, central memory and effector memory $\mathrm{T}$ cells to dendritic cell-mediated HIV-1 transmission. Retrovirology 3: 52, 2006.

25. Ugel S, Peranzoni E, Desantis G, Chioda M, Walter S Weinschenk T, Ochando JC, Cabrelle A, Mandruzzato S and Bronte V: Immune tolerance to tumor antigens occurs in a specialized environment of the spleen. Cell Rep 2: 628-639, 2012.

26. Levy L, Mishalian I, Bayuch R, Zolotarov L, Michaeli J and Fridlender ZG: Splenectomy inhibits non-small cell lung cancer growth by modulating anti-tumor adaptive and innate immune response. Oncoimmunology 4: e998469, 2015.

27. Hashimoto N, Shimoda S, Kawanaka H, Tsuneyama K, Uehara H Akahoshi T, Kinjo N, Taketomi A, Shirabe K, Akashi K, et al: Modulation of CD4+ T cell responses following splenectomy in hepatitis $C$ virus-related liver cirrhosis. Clin Exp Immunol 165: 243-250, 2011.

28. Sumida K, Shimoda S, Iwasaka S, Hisamoto S, Kawanaka H Akahoshi T, Ikegami T, Shirabe K, Shimono N, Maehara Y, et al: Characteristics of splenic CD8+ T cell exhaustion in patients with hepatitis C. Clin Exp Immunol 174: 172-178, 2013.

29. Lindau D, Gielen P, Kroesen M, Wesseling P and Adema GJ The immunosuppressive tumour network: Myeloid-derived suppressor cells, regulatory $\mathrm{T}$ cells and natural killer T cells. Immunology 138: 105-115, 2013.

30. Mizukoshi E, Yamashita T, Arai K, Terashima T, Kitahara M, Nakagawa H, Iida N, Fushimi K and Kaneko S: Myeloid-derived suppressor cells correlate with patient outcomes in hepatic arterial infusion chemotherapy for hepatocellular carcinoma. Cancer Immunol Immunother 65: 715-725, 2016.

31. Long X, Wang J, Zhao JP, Liang HF, Zhu P, Cheng Q, Chen Q, Wu YH, Zhang ZG, Zhang BX and Chen XP: Splenectomy suppresses growth and metastasis of hepatocellular carcinoma through decreasing myeloid-derived suppressor cells in vivo. J Huazhong Univ Sci Technolog Med Sci 36: 667-676, 2016.

32. Huang CH, Jeng WJ, Ho YP, Teng W, Chen WT, Chen YC, Lin SM, Chiu CT, Sheen IS and Lin CY: Increased regulatory $\mathrm{T}$ cells in patients with liver cirrhosis correlated with hyperbilirubinemia and predict bacterial complications. J Gastroenterol Hepatol 30: 775-783, 2015.
33. Nagai H, Mukouzu T, Matsui D, Kanekawa T, Matsui T, Kanayama M, Wakui N, Momiyama K, Shinohara M, Ishii K, et al: Host Immunity influences the efficacy of combined intra-arterial chemotherapy for advanced hepatocellular carcinoma in liver cirrhosis patients. Hepatogastroenterology 61: 741-746, 2014.

34. Romano A, Hou X, Sertorio M, Dessein H, Cabantous S, Oliveira P, Li J, Oyegue S, Arnaud V, Luo X, et al: Foxp3+regulatory T cells in hepatic fibrosis and splenomegaly caused by schistosoma japonicum: The spleen may be a major source of tregs in subjects with splenomegaly. PLoS Negl Trop Dis 10: e0004306, 2016.

35. Bedard M, Salio M and Cerundolo V. Harnessing the power of invariant natural killer T cells in cancer immunotherapy. Front Immunol. 18: 1829, 2017.

36. Sekiguchi T, Nagamine T, Takagi H and Mori M: Reduction of virus burden-induced splenectomy in patients with liver cirrhosis related to hepatitis $\mathrm{C}$ virus infection. World J Gastroenterol. 7: 2089-2094, 2006.

37. Kawarabayashi N, Seki S, Hatsuse K, Ohkawa T, Koike Y, Aihara T, Habu Y, Nakagawa R, Ami K, Hiraide $H$ and Mochizuki H: Decrease of CD56(+)T cells and natural killer cells in cirrhotic livers with hepatitis $\mathrm{C}$ may be involved in their susceptibility to hepatocellular carcinoma. Hepatology 32: 962-969, 2000

38. Yang CM, Yoon JC, Park JH and Lee JM: Hepatitis C virus impairs natural killer cell activity via viral serine protease NS3. PLoS One 14: e0175793, 2017.

39. Poli A, Michel T, Thérésine M, Andrès E, Hentges $F$ and Zimmer J: CD56bright natural killer (NK) cells: An important NK cell subset. Immunology 126: 458-465, 2009.

40. Wang J, Han W, Gao Z, Wang Y, Wu L, Zhang J, Lai W and Wang Z: Elevation of $\mathrm{CD}^{+} 6^{+} \mathrm{CD} 56^{+} \mathrm{NK}$-cells and down-regulation of serum interleukin-21 (IL-21) and IL-1 $\alpha$ after splenectomy in relapsed hemophagocytic lymphohistiocytosis of unknown cause. Hematology 22: 477-483, 2017.

41. Goh CC, Roggerson KM, Lee HC, Golden-Mason L, Rosen HR and Hahn YS: Hepatitis C virus-induced myeloid-derived suppressor cells suppress NK cell IFN- $\gamma$ production by altering cellular metabolism via arginase-1. J Immunol 196: 2283-2292, 2016.

42. Kawaguchi T, Komori A, Seike M, Fujiyama S, Watanabe H, Tanaka M, Sakisaka S, Nakamuta M, Sasaki Y, Oketani M, et al: Efficacy and safety of eltrombopag in Japanese patients with chronic liver disease and thrombocytopenia: A randomized, open-label, phase II study. J Gastroenterol 47: 1342-1351, 2012.

43. Sakamaki A, Watanabe T, Abe S, Kamimura K, Tsuchiya A, Takamura M, Kawai H, Yamagiwa S and Terai S: Lusutrombopag increases hematocytes in a compensated liver cirrhosis patient. Clin J Gastroenterol 10: 261-264, 2017.

44. Matsukiyo Y, Nagai H, Matsui T and Igarashi Y: Host immunological effects of partial splenic embolization in patients with liver cirrhosis. J Immunol Res 2018: 1746391, 2018.

45. Santegoets SJ, Dijkgraaf EM, Battaglia A, Beckhove P, Britten CM, Gallimore A, Godkin A, Gouttefangeas C, de Gruijl TD, Koenen HJ, et al: Monitoring regulatory T cells in clinical samples: Consensus on an essential marker set and gating strategy for regulatory $\mathrm{T}$ cell analysis by flow cytometry. Cancer Immunol Immunother 64: 1271-1286, 2015. 